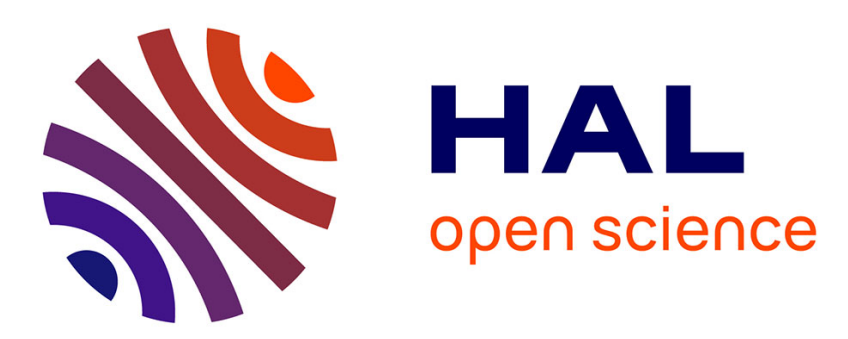

\title{
Cardiac response to live music performance: effect of large-scale musical structure on action potential duration
}

Elaine Chew, Peter Taggart, Pier Lambiase

\section{To cite this version:}

Elaine Chew, Peter Taggart, Pier Lambiase. Cardiac response to live music performance: effect of large-scale musical structure on action potential duration. EP-Europace, 2020, 10.1093/europace/euaa162.136 . hal-03277679

\section{HAL Id: hal-03277679 \\ https://hal.science/hal-03277679}

Submitted on 4 Jul 2021

HAL is a multi-disciplinary open access archive for the deposit and dissemination of scientific research documents, whether they are published or not. The documents may come from teaching and research institutions in France or abroad, or from public or private research centers.
L'archive ouverte pluridisciplinaire HAL, est destinée au dépôt et à la diffusion de documents scientifiques de niveau recherche, publiés ou non, émanant des établissements d'enseignement et de recherche français ou étrangers, des laboratoires publics ou privés. 
Title (200 characters max)

Cardiac response to live music performance: effect of large-scale musical structure on action potential duration

\author{
Authors \\ Elaine Chew, Peter Taggart, Pier Lambiase
}

\title{
Abstract Evaluation Topic (3000 characters max) 36.3.4 - Basic Science - Cardiac Diseases: Arrhythmias
}

Background: Strong emotions can trigger cardiac arrhythmias, but the heart-brain mechanism by which they do so is not well understood. Music induces strong emotions, precipitated by musical changes and intensified during live performance; it thus serves as a powerful tool through which to investigate heart-brain interaction. However, existing studies use short, artificial or pre-recorded music excerpts, out of context and classified into singular, simple emotion classes over which aggregate response are reported, ignoring the range of responses possible for the same music stimulus. None has considered electrical response to music as measured from the heart muscles.

Purpose: To evaluate the impact on action potential duration due to musical changes at large-scale structural boundaries in live music performance.

Methods: Patients implanted with biventricular pacemakers/ICDs are invited to a live classical piano concert. Prior to the concert, the patients' pacemakers are programmed from CRT to dual chamber pacing at $80 \mathrm{bpm}$ or ten above their intrinsic heart rate. Following a ten-minute adjustment period, they listen to three pieces lasting 15 minutes; this was subsequently expanded to five lasting 30 minutes. Continuous recordings of the intracardiac electrogram (EGM) signals are downloaded from the ICD lead connected to the left ventricle whilst the patients listen to the music. The pacemakers are returned to their original settings after the concert. The patients further provide annotations for perceived change boundaries and tension, as well as information on their music training/experience. We approximate the action potential duration (APD) using the action recovery interval (ARI) extracted from the EGM signal, and compare the ARIs before and after each structural boundary indicated in the music score.

Results: We analyze the ARI data surrounding 24 music structural boundaries. The first results are for the three patients (two male; one female) from the initial study day. We perform a two-sample t-test to assess the population means in ARI values before and after each of the 24 structural boundaries. The figure attached shows the statistically significant changes across structural boundaries for $\alpha=0.05$; the bar plots show the sample means and 95\% confidence intervals (CI) for the 80 ARIs before and after a boundary, and report the p-values of the t-tests. Patients 1 and 3 each reacted significantly to three out of the 24 boundaries (12.5\%), sometimes in opposite directions, and Patient 2 to 15 out of the 24 boundaries (62.5\%). The CIs for the significant differences spanned the range $(-4.4896,4.8745)$.

Conclusions: We show that structural boundaries, where music features change or transition, can produce significant changes in APD. A range of significant responses are observed, including contradictory ones, that span a nearly $10 \mathrm{~ms}$ range, which could play a contributory role to clinical understanding of arrhythmias and emotion responses. 


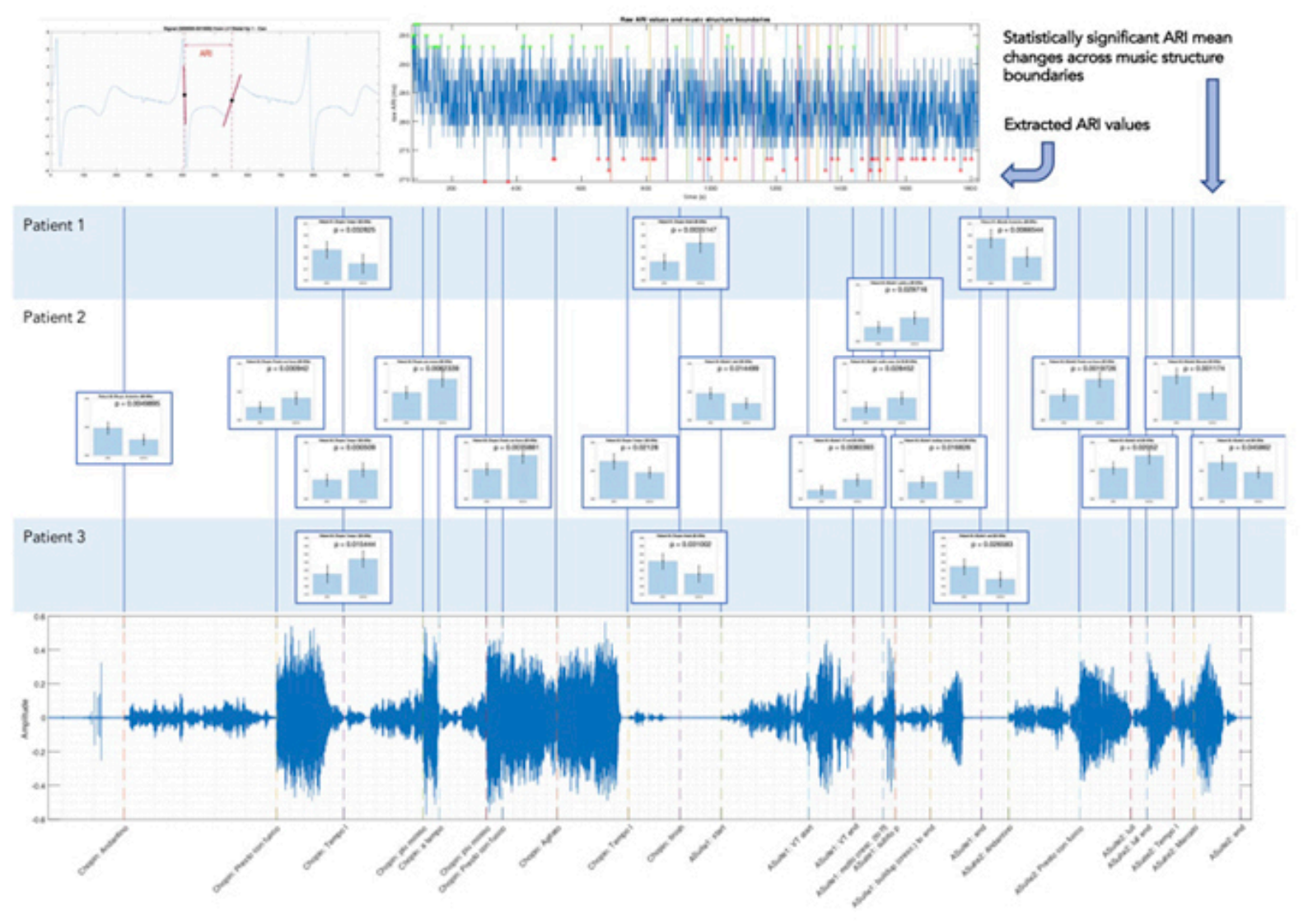

